\title{
Povos indígenas no cenário das discussões sobre desenvolvimento sustentável: contextualização das propostas dos povos indígenas do Alto Rio Negro
}

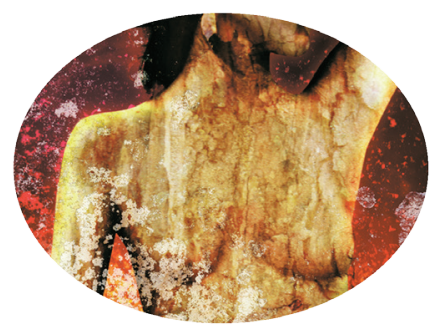

Jocilene Gomes da Cruz* Doris Aleida Villamizar Sayago**

\section{Resumo}

Neste artigo são evidenciadas as discussões acerca da noção de desenvolvimento sustentável, particularmente o panorama da apropriação e ressignificação desta pelos povos indígenas. Como foco de análise apresenta-se a participação dos povos indígenas do alto rio Negro, representados pelas associações formais que compõem a Federação das Organizações do Rio Negro (Foirn), na elaboração de projetos e programas de desenvolvimento sustentável com o propósito de viabilizar alternativas econômicas sustentáveis, valorização da diversidade cultural e dos conhecimentos dos povos indígenas da região. Dentre essas propostas destaca-se o Programa Regional de Desenvolvimento Indígena Sustentável (PRDIS) e o Sistema de Sustentabilidade do Rio Negro, estruturados pelos indígenas e seus parceiros - organizações governamentais e entidades do terceiro setor - especificamente o Instituto Socioambiental que é parceiro da Foirn há 25 anos. As discussões empreendidas neste artigo são feitas a partir da análise de referenciais teóricos e de pesquisa documental em fontes como os relatórios e os documentos produzidos nos eventos realizados pela Foirn, tais como encontros, seminários, fóruns e assembleias nos quais foi tratada a questão da sustentabilidade da região. De modo a evidenciar a importância do protagonismo dos povos indígenas em torno da conservação

\footnotetext{
* Doutoranda do Programa de Pós-Graduação em Ciências do Ambiente e Sustentabilidade na Amazônia (Ufam). Bolsista da Fundação de Amparo à Pesquisa do Estado do Amazonas. E-mail: jocilene.am@gmail.com

** Doutora em Sociologia, professora do Centro de Desenvolvimento Sustentável da Universidade de Brasília (CDS/UnB). E-mail: doris.sayago@gmail.com
} 
de seus territórios, apresenta-se a trajetória do movimento indígena, a constituição de suas associações formais na luta pela demarcação das terras e sua mobilização político-cultural demandando a implementação de políticas públicas para a conservação das terras. Considera-se que essa trajetória fornece elementos importantes para a compreensão dos mecanismos de participação utilizados pelos povos indígenas no contexto atual, como a apropriação por parte destes de categorias não indígenas, utilizadas como instrumentos para o fortalecimento da identidade étnica e de suas formas peculiares de instituição representativa e de autonomia.

Palavras-chave: desenvolvimento sustentável; povos indígenas; Alto rio Negro; Sustentabilidade.

\section{Abstract}

Discussions on the concept of Sustainable Development, particularly its view of the appropriation and redefinition by indigenous peoples, are highlighted in this article. As the focus of analysis, it is exhibited the participation of indigenous peoples from Upper Rio Negro, which are represented by formal Associations that integrate the Federation of Organizations of the Rio Negro (Foirn), in projects and programs of sustainable development, elaborated with the purpose of enabling economic sustainable alternatives in the region, as well as valorization of cultural diversity and knowledge of indigenous peoples. Among these proposals, it is stood out the Regional Program for Sustainable Indigenous Development (PRDIS) and the Sustainability of Rio Negro System, both structured by the Indigenous and their partners, governmental organizations and entities from the third sector, specifically the Environmental Institute, which is Foirn's partner from the last 25 years. The discussions undertaken in this article are done from the analysis of theoretical references and documentary research on sources such as reports and documents produced in events held by Foirn, such as meetings, seminars, forums and assemblies in which the issue of sustainability of the region was considered. In order to highlight the importance of the role of indigenous peoples around the conservation of their territories, it is exhibited the trajectory of the indigenous movement, the establishment of formal associations in their struggle for land demarcation and its political and cultural mobilization demanding the implementation of public policy for the land 
conservation. It is considered that this path provides important elements for understanding the mechanisms of participation used in the current context by indigenous peoples, as their appropriation of non-indigenous categories, used as a mechanism for strengthening ethnic identity and their peculiar ways of representative institution and autonomy.

Keywords: sustainable development; indigenous peoples; Upper rio Negro; sustainability.

\section{Introdução}

As discussões em destaque neste artigo versam, em termos gerais, em torno de uma postura que privilegia a percepção sobre os povos indígenas como sujeitos históricos e políticos atuantes nos contextos de interlocução cultural visando à conservação de suas terras e de suas culturas. Trazendo uma abordagem que evidencia os movimentos de reelaboração ou ressignificação do ambiente em que estão inseridos e das relações interétnicas estabelecidas neste na atualidade.

É a partir dessa perspectiva que se analisa a participação dos povos indígenas do alto rio Negro na implementação de programas e projetos pautados na noção de desenvolvimento sustentável, a exemplo do Programa Regional de Desenvolvimento Indígena Sustentável (PRDIS), estruturado a partir de 1998, logo após a demarcação das Terras Indígenas, e o Sistema de Sustentabilidade do Rio Negro, divulgado em fevereiro de 2012, ambos considerados, pelos indígenas, como mecanismos para a conservação das Terras Indígenas demarcadas.

Trata-se de um novo cenário, sendo importante destacar que este é delineado pela atuação do "movimento indígena" consolidado em meados da década de 80 , o qual se configura na união dos povos indígenas em torno de lutas e reivindicações comuns - a defesa de sua existência física e cultural, sendo que a garantia da integridade das Terras Indígenas, compreendida como condição de suas existências étnicas em virtude da intrínseca relação entre estes.

Destaca-se que foi mediante a luta do movimento indígena de todo o Brasil, com apoio de seus aliados, a incorporação na Constituição Brasileira de 1988 de um capítulo que defende os direitos dos indígenas, sendo essa lei 
transformada em bandeira de luta para assegurar a demarcação de suas terras, e, sobretudo, a forma de vida tradicional de cada povo. Ela também propiciou a estruturação de novas organizações formais (as associações indígenas) em nível estadual, nacional e até internacional.

No Brasil, muitas organizações indígenas foram instituídas. No Estado do Amazonas, algumas delas estão organizadas em confederações, destacando-se a Federação das Organizações Indígenas do Rio Negro (Foirn), a qual congrega 90 associações indígenas formais (FOIRN, 2012). No âmbito internacional, os direitos indígenas foram reconhecidos por meio de aparatos legais como a Convenção 169, da Organização Internacional do Trabalho (OIT), e a Convenção sobre Diversidade Biológica (CDB), sendo esta última inovadora, pois inseriu em um instrumento legal internacional uma abordagem inclusiva da proteção da biodiversidade associada às boas práticas, saberes e inovações da sociodiversidade.

Peres (2003: 30) observa que hoje os povos indígenas “incorporaram a agenda e a linguagem ambientalista e construíram o elo entre as demandas de conservação da natureza e as de defesa dos direitos humanos". Cabe assinalar que, nesse contexto, verifica-se a estruturação de uma rede de cooperação estabelecida pelos indígenas com as instituições governamentais e as não governamentais, visando à gestão dos territórios que foram demarcados e homologados, mas que estão constantemente ameaçados pela atuação de agentes externos como madeireiros, pecuaristas, garimpeiros e outros. Destaca-se que é nesse contexto que constroem suas versões de desenvolvimento sustentável, as quais passam a ser incorporadas em seus discursos político-culturais em defesa de suas terras.

\section{O paradigma ocidental de progresso e a noção de Desenvolvimento Sustentável: preâmbulo de uma análise necessária}

A ideia de desenvolvimento pautado no paradigma ocidental de progresso, na perspectiva de Morin (2000), fez consolidar em nós a fé cega no progresso, entendido como uma tríade ciêncialtécnicalindústria, sob a qual as sociedades alcançariam o bem-estar, resolveriam suas desigualdades e solucionariam os problemas que se apresentassem. Dessa convicção constituiuse a ideia de que todas as forças devem ser direcionadas em busca desse modelo 
de desenvolvimento, sendo que, na análise do autor, verifica-se que esse modelo determina, além da degradação dos recursos naturais, o acirramento dos problemas sociais, criando-se um "subdesenvolvimento" cada vez mais subjugado aos interesses dos que se tornaram desenvolvidos.

Essas observações conduzem a uma análise crítica acerca de nossa sociedade revelando que o prometido não se cumpriu, e poucos foram beneficiados por esse modelo. O "ideal evolucionista" sustentado pela tríade ciência/técnica/indústria não conseguiu cumprir seu papel providencial e, infelizmente, o desenvolvimento que se daria em todos os aspectos (sociais, psíquicos e morais) acabou por propiciar inúmeros impactos negativos sobre os modos de vida e o ambiente.

Nesse sentido, tal ideia de desenvolvimento caracteriza-se por ignorar as riquezas culturais das sociedades, as quais foram vistas de forma equivocada, não sendo reconhecidos os saberes milenarmente acumulados. As noções de desenvolvimento e progresso, como noções neutras e universalmente desejadas, permitem tão somente obscurecer as relações de poder e domínio (econômico, político, cultural, tecnológico, entre outros) que ocorrem tanto no interior das nações quanto nas nações entre si.

Uma análise, igualmente crítica, é apresentada por Furtado (1998: 14), para o qual as concepções de desenvolvimento e progresso do modelo capitalista não passam de mitos, tendo como função apenas encobrir a dominação dos povos e dos países periféricos. Pois levam a crer que é possível ser universalizado o desenvolvimento econômico praticado pelos países desenvolvidos, quando na prática isso se revela inviável, tendo em vista, entre outros fatores, o seu caráter predatório. A partir desse pressuposto, o autor destaca que em nossa sociedade a criação de valor essencialmente econômico provoca, na grande maioria dos casos, processos irreversíveis de degradação do ambiente.

Os questionamentos referentes ao modelo de desenvolvimento capitalista levantaram inúmeras discussões, nas quais se evidenciou a necessidade de se estabelecer um novo modelo de desenvolvimento que leve em consideração os custos sociais e ambientais. Essas discussões surgem num período em que se observa a movimentação de grupos que defendem a urgência de substituí-lo por um outro modelo, pautado no respeito ao ser humano e ao meio ambiente, sendo que, nesse contexto, paulatinamente são delineadas formulações 
referentes à noção de desenvolvimento sustentável, como modelo alternativo ao vigente.

É possível, no momento atual, encontrar uma vasta literatura referente às discussões concernentes à noção de desenvolvimento sustentável, a qual aparece oficialmente em 1983, tendo como propósito estabelecer novas prioridades à sociedade, como: recuperação do primado dos interesses sociais coletivos, nova ética do comportamento humano e mudanças na estrutura de produção e consumo, que possam intervir no quadro de degradação ambiental. Esse discurso passa a ser amplamente reproduzido, tanto nos debates acadêmicos como também entre políticos, empresários, dentre outros. Um dos responsáveis pela disseminação desses propósitos foi o Relatório Brundtland, mais conhecido como Nosso Futuro Comum, organizado por uma equipe de especialistas da Organização das Nações Unidas (ONU), com a finalidade de fazer um balanço do desenvolvimento econômico em termos mundiais, as consequências socioambientais resultantes desse modelo e a propor estratégias de longo prazo, visando o desenvolvimento sustentável.

A noção de desenvolvimento apresenta uma conotação qualitativa que implica melhoria da qualidade de vida, envolvendo múltiplos aspectos de ordem econômica, social, política, entre outros. No entanto, tende-se a associá-la a critérios puramente quantitativos de medição do crescimento econômico, gerando interpretações restritas, e, por isso, criticadas. Nesse sentido, a discussão a respeito das definições de desenvolvimento, no contexto presente, reveste-se de um caráter extremamente complexo, principalmente pelo fato de ser "confundido" com crescimento econômico.

No que concerne à noção de sustentabilidade, verifica-se que há também um emaranhado de definições, as quais geralmente incluem temas relacionados com a dimensão ecológica, econômica e social. A operacionalização dos ideais da sustentabilidade são igualmente apontados como grandes desafios, em função da falta de clareza em relação a sua implementação. As dificuldades se fazem perceber desde o campo conceitual, pois as definições são abrangentes e se inscrevem num campo maior: o das relações entre os homens entre si e com a natureza, envolvendo uma série de propósitos que se contrapõem à noção de desenvolvimento, que é confundida e/ou relacionada exclusivamente com crescimento.

Para Sachs (1993), a noção de desenvolvimento sustentável deve ser 
entendida como um processo de aprendizagem social, com uma dimensão histórica e cultural, devendo levar a uma atitude "pró-ativa" diante dos problemas. Para tanto, o crescimento econômico deveria submeter-se às regras de uma distribuição social equitativa e às imposições ecológicas, diferentemente do que é visto no modelo capitalista.

Ainda à luz das análises do autor, o desenvolvimento sustentável precisa ser endógeno, ou seja, nascer dentro de uma dada sociedade por iniciativa desta, e os projetos estruturados pelos membros dessa sociedade de acordo com suas especificidades, não algo induzido, trazido por força do desejo de outrem. Sachs apresenta o que considera os cinco pilares da endogeneidade, a saber: "oposto ao crescimento mimético, autoconfiança (oposta à dependência), orientação por necessidades (em oposição à orientação pelo mercado); harmonia com a natureza e abertura à mudança institucional" (SACHS, 2004: 12).

Nessa perspectiva, fica também explicita a necessidade de se distinguir desenvolvimento de crescimento econômico, e de se compreender que os objetivos do desenvolvimento vão bem além da mera multiplicação da riqueza material. Isso porque, de acordo com o autor, "o crescimento é uma condição necessária, mas de forma alguma suficiente (muito menos é um objetivo em si mesmo), para se alcançar a meta de uma vida melhor, mais feliz e mais completa para todos" (Ob. cit., p. 13).

Cabe também destaque as observações feitas por Leff (2009) concernentes ao desenvolvimento sustentável. O autor inicia suas análises destacando que se criou em nossa sociedade uma racionalidade insustentável, demandando de nós buscar mecanismo para reverter tal situação e recuperar o sentido da vida a partir de uma "contrarracionalidade ambiental", com a construção de novos conhecimentos capazes de nos colocar novamente dentro da natureza. Pois a racionalidade vigente pauta-se numa compreensão de economia que se alimenta de uma natureza destruída, vista como objeto, foi ela quem tirou a cultura de dentro da natureza. Trata-se de uma racionalidade que ignora o fato de os recursos naturais serem finitos, inviável a todas as sociedades de atingirem o mesmo padrão de consumo praticado nos países ditos desenvolvidos.

Ainda, conforme o autor, um princípio importante para alcançar um modelo sustentável passa pela compreensão do exercício da democracia ambiental, do respeito a outras formas de produzir, como a desenvolvida pelos seringueiros que se empenham em criar reservas não meramente para um 
sentido contemplativo, mas para a subsistência de suas famílias, apresentando formas próprias de produzir essa subsistência. Isso também se aplica aos povos indígenas com seus modos peculiares de produzir sua subsistência, culturas muito criativas e eficientes nesse propósito e que precisam ser respeitadas.

Assim, em termos gerais, verifica-se que essa nova racionalidade ambiental apontada pelo autor pressupõe ética nas relações sociais, valorização da diversidade cultural, bem como chama a atenção para a importância dos conhecimentos tradicionais, como o dos povos indígenas os quais, durante milênios, têm estabelecido relação respeitosa com o seu meio ambiente, visto por estes como algo do qual fazem parte, no qual os seres vivos se relacionam, interagem e são responsáveis por uma existência comum, muito diferente da racionalidade produzida no interior do sistema capitalista de produção.

Ao contextualizar os problemas ambientais no Brasil, Cavalcante (2002: 24) também faz uma crítica à visão de economia e desenvolvimento que permeia a racionalidade capitalista, enfatizando que a estruturação das políticas públicas no Brasil tendem, erroneamente, a pautar-se na visão da ciência econômica convencional, a qual não considera a base ecológica do sistema econômico dentro de seu arcabouço analítico levando assim "a crença no crescimento ilimitado", quando a ideia de sustentabilidade, por sua vez, implica uma "limitação definida nas possibilidades de crescimento".

$\mathrm{O}$ autor enfatiza também que um dos princípios fundamentais a ser considerado quando da formulação de política pública, visando à sustentabilidade, refere-se à necessidade da disposição de um sistema consistente de informação para avaliar o desenvolvimento econômico de um país ou região. Contudo, sem perder o foco de que numa sociedade sustentável "o progresso deve ser apreendido pela qualidade de vida (saúde, longevidade, maturidade psicológica, educação, um meio ambiente limpo, espírito de comunidade, lazer gozado de modo inteligente, e assim por diante), e não pelo puro consumo material" (CAVALCANTE, 2002: 28), lembrando que renda nacional e o Produto Interno Bruto por pessoa referem-se a progresso material. Infelizmente quando uma política prioriza apenas o progresso econômico o resultado é negativo, pois promove problemas ambientais. Uma política de governo para a sustentabilidade, por sua vez, significa uma orientação das ações públicas motivadas pelo reconhecimento da limitação ecológica fundamental dos recursos, sem os quais nenhuma atividade humana pode se realizar. 
Cabe assinalar que os autores aqui elencados partem de um ponto de análise comum - uma visão crítico-reflexiva sobre a noção de desenvolvimento - chamando a atenção para a necessidade de esta ser entendida a partir de uma visão qualitativa, sendo imprescindível no cenário das discussões sobre o desenvolvimento sustentável problematizar essa compreensão, e trazer à tona questões como ética nas relações sociais, respeito à diversidade e considerar a relação intrínseca entre homem-natureza, a qual, ao longo dos anos/séculos, foi se desestruturando.

\section{Povos indígenas no cenário das discussões sobre o Desenvolvimento Sustentável}

Em páginas precedentes, foram destacadas algumas discussões teóricas que evidenciam as contradições que perpassam pelo campo conceitual e prático da noção de desenvolvimento sustentável, destacando-se que essas contradições podem ser percebidas pela adoção deste, por parte de agentes representativos da visão desenvolvimentista.

$\mathrm{Na}$ análise de Pareschi (2004: 154), o desenvolvimento sustentável seria mais uma "versão da dinâmica adaptativa do próprio desenvolvimento, em que a sustentabilidade em nada tem a ver com as preocupações ecológicas e sociais". Tratando-se de uma questão a ser considerada, contudo, não se limitando a ela, pois é também importante avaliar a "complexidade semântica e política desse conceito, que tanto os agentes defensores do desenvolvimento não sustentável quanto os agentes que buscam mudanças se apropriam" (Ob. cit., p. 156). Ao apontar essas questões, a autora chama a atenção para a dinamicidade das sociedades, que diante de situações adversas reagem de forma criativa, assim "culturas são ressignificadas pela história em curso dos acontecimentos".

Acerca dessas preposições, Leite Lopes (2006: 50) assinala que os cidadãos, ao serem atingidos por problemas ambientais, se apropriam de forma criativa do discurso ambientalista, e também criam formas peculiares de associativismo como mecanismo para a resolução das questões socioambientais. É nesse contexto que se dá a "ambientalização dos conflitos sociais", a qual está relacionada à construção de uma "nova questão social e pública”. Assim, ao participarem de encontros em que se discutem os problemas ambientais, 
"grupos como pescadores, trabalhadores rurais, 'povos da floresta', operários preocupados com a saúde do trabalhador apropriam-se das questões, da linguagem e da argumentação ambiental para engrandecerem-se em conflitos com seus eventuais oponentes".

Nesse sentido, os argumentos ambientalistas apropriados por distintos grupos sociais servem, sobretudo, para fortalecer suas mobilizações contra os problemas que põem em risco seus territórios e/ou a integridade física e cultural. O que representa a consolidação, no contexto atual, da participação destes na questão pública do meio ambiente, na qual se observam conquistas significativas como a criação de áreas protegidas, por exemplo.

Essa apropriação, como bem assinala Almeida (2005), faz parte das estratégias de interlocução entre grupos sociais e setores do Estado que envolvem "argumentação, disputa e negociação sob a égide da dimensão ambiental". O autor enfatiza que a adoção dos argumentos e da linguagem propriamente dita do ambientalismo, por parte desses grupos sociais, não pode ser confundida com um simples uso de discursos, pois ocorre, na realidade, uma ressignificação destes, algo que se torna muito peculiar às populações e aos povos que os ressignificam.

No que concerne, especificamente, à adoção da noção de desenvolvimento sustentável pelos povos indígenas, Pimenta (2010: 97) evidencia a necessária reflexão sobre o "lugar dos povos indígenas na cena amazônica contemporânea do desenvolvimento sustentável”, e assinala que é preciso considerar que podem existir lugares diversos, dependendo das relações sociais que estabelecem com o universo não indígena.

No caso específico do povo Ashaninka, o autor observa que para estes a "ideologia" do desenvolvimento sustentável lhes "permite encontrar uma maior audiência e dar mais peso às suas reivindicações políticas e culturais" (Ob. cit., p. 98). Pois, durante anos, estes chamaram a atenção para os problemas que vivenciavam; contudo, sem êxito, porém ao incorporarem o discurso ambientalista o cenário mudou, assinalando que

os índios da Amazônia alcançaram uma visibilidade inédita e encontraram novas modalidades de ação para concretizar suas reivindicações político-culturais. Ao manipularem símbolos, índios e ambientalistas criaram um novo espaço político de alianças interculturais que se traduziram 
em resultados surpreendentes: demarcação de Terra Indígena, criação de unidades de conservação, de reservas extrativistas, de parques nacionais etc. (PIMENTA, 2010: 107).

De acordo com o autor, apesar de intimamente ligado ao Ocidente, a "ideologia" do desenvolvimento sustentável não deve ser considerada incompatível com os povos indígenas, pois em muitos casos geram, de fato, melhorias consubstancias nos locais onde são incorporadas, criando espaços políticos de alianças interculturais que se traduzem em resultados positivos. Contudo, deve-se ter claro que a concepção de natureza, bem como a relação homem-natureza dos povos indígenas é distinta da não indígena. Portanto, embora utilizem uma categoria não indígena (desenvolvimento sustentável), os princípios de suas ações tem como motivação, de fato, a proteção do ambiente no qual se inserem e com o qual possuem relação material e espiritual muito diferente da observada na sociedade ocidental.

Essas questões foram problematizadas por Albert (2002), o qual centra suas análises particularmente no discurso ambientalista que foi incorporado ao discurso político dos povos indígenas nos anos 90, momento em que se inicia o processo por ele denominado de "ecologização do discurso indígena". Esse processo, de acordo com o autor, "incorporou categorias 'brancas' da etnificação, como 'território', 'cultura' e 'meio ambiente', tendo sido catalisado pela retórica indigenista da Igreja e de organizações não governamentais num momento em que as lutas dos povos indígenas tiveram lugar na mídia mundial e o ambientalismo sensibilizava os países industrializados" (ALBERT, 2002: 241).

O autor enfatiza ainda que a defesa e a preservação de sociedades indígenas, justificada pela sua posição de "ecologistas espontâneos", vistos como populações em perfeita continuidade com o seu meio ambiente, está no imaginário de muitos. Para este, no entanto, não se trata de uma manipulação dos indígenas por agentes indigenistas e ambientalistas, mas de um "processo político-cultural de adaptação criativa que gera as condições de possibilidade de um campo de negociação interétnica, em que o discurso colonial possa ser contornado ou subvertido" (ALBERT, 2002: 260). Essas observações são feitas tendo como referência a análise do discurso político-cultural do líder Yanomami Davi Kopenawa, para o autor: 
[...] o discurso ambientalista, longe de ser uma mera retórica de circunstância, passou a ser o meio de simbolização intercultural adequado à expressão e à validação de uma visão do mundo e de um projeto Yanomami na cena nacional e internacional. Davi observa o discurso ambientalista das ONGs com grande interesse, mas sem complacência. Vê nele um dispositivo de tradução cultural estratégico para construir a história presente de seu povo.

É importante destacar que esse cenário não pode ser analisado sem contextualizar a participação das organizações formais indígenas e o crescente processo de associativismo que representam. Pois é por meio destas que os povos indígenas se mobilizam em torno das "questões ambientais" e da implementação de projetos pautados na noção de desenvolvimento sustentável.

De acordo com Lima (2010: 23), os povos indígenas no Brasil contemporâneo "lutam por obter capacidades de outra natureza, a que possam recorrer para além de seus conhecimentos próprios no enfrentamento de realidades geradas por outro patamar de dependência", ou seja, o autor chama a atenção para as modificações verificadas nas terras e comunidades indígenas que necessitam de novas estratégias de ação, de modo a atender as demandas geradas pelo processo histórico de contato com os não indígenas.

Nesse sentido, são essas modificações responsáveis pela procura dos povos por cursos de capacitação e mesmo formação universitária em áreas específicas entendidas, por estes, como estratégias viáveis à resolução de seus problemas. Vale assinalar que essa procura por outros conhecimentos não se dá em substituição de seus conhecimentos tradicionais; ao contrário, estes são percebidos como essenciais no processo, ocorrendo apenas acréscimos de saberes, que somados aos seus, entendem serem capazes de viabilizar melhorias nos locais onde habitam.

\section{Estruturação e implementação de propostas de desenvolvimento sustentável no alto rio Negro}

Antes de focar as atuais propostas dos povos indígenas do alto rio Negro de desenvolvimento sustentável da região, compreendidas como 
mecanismos para a gestão territorial e ambiental de suas terras, faz-se uma breve contextualização dos acontecimentos históricos que marcaram as relações interétnicas entre os povos indígenas e os não indígenas que chegaram na região. Considera-se que estes fatos são importantes para compreender as dinâmicas socioculturais que envolvem as discussões e a implementação dessas propostas.

A região do alto rio Negro situa-se no extremo noroeste do Estado do Amazonas, onde habitam 23 povos indígenas pertencentes a três grandes famílias linguísticas: Tukano Oriental, Aruak e Maku; são cerca de 30.000 pessoas que vivem nas comunidades localizadas nas cinco Terras Indígenas que foram demarcadas e homologadas em abril de 1998, bem como nas demais que ainda se encontram em processo de reconhecimento legal (FOIRN/ISA, 2003).

Trata-se de uma região com características peculiares, especialmente no que diz respeito ao protagonismo indígena, são cerca de 90 associações formais, congregadas à Federação das Organizações Indígenas do Rio Negro (Foirn) formando uma estrutura coesa, que funciona como eficaz mecanismo de mobilização coletiva, por meio da qual lutam para garantir os direitos dos povos indígenas da região em termos de saúde, educação e subsistência em suas terras tradicionais.

Conforme aponta uma vasta literatura ${ }^{1}$, a região do rio Negro iniciou seu “contato" com os não indígenas por volta dos séculos 16 e 17. Os estudos de Jackson (1983) e Cabalzar Filho (1995) destacam que a atuação dos missionários estava, nesse período, relacionada às formas de recrutamento da mão de obra indígena, as chamadas tropas de resgates e descimentos. Nos séculos 19 e 20, essa atuação se vincula às Políticas Nacionais de "catequese e civilização" dos povos indígenas, sendo que no período auge do extrativismo da borracha essa influência diminui.

No século 20, depois dos grandes genocídios ocorridos no período colonial, os povos indígenas concentrados ainda mais nos altos cursos dos rios, passam a ser alvo dos propósitos da catequização da Ordem dos Salesianos que chega à região. Os autores ora citados enfatizam que a ação desses missionários, por um lado, significou uma redução dos abusos dos patrões que até então predominavam, por outro lado, criou um estado de submissão e assimilação dos povos indígenas mediante a imposição dos preceitos religiosos 
que representavam.

Nesse mesmo século chega à região os missionários evangélicos norteamericanos da Missão Novas Tribos (MNT), liderados por Sophia Müller, e a partir de 1940 iniciam suas incursões no médio e alto rio Negro, dando-se nesse período a separação entre índios católicos e evangélicos. Peres (2003: 22), ao analisar a atuação dos missionários (católicos e evangélicos) na região, resgata os estudos de Robin Wright feitos nos anos de 1981 a 1999, nos quais apresenta os povos indígenas como "personagens ativos" no trágico processo histórico de contato, e não como meros espectadores de um processo assimilacionista irremediável, ou seja, mostra quanto os povos indígenas lutaram contra esse processo e como empreenderam inúmeras estratégias de luta, as quais pouco são mencionadas nos relatos históricos.

Nesse breve relato sobre os antecedentes históricos da região do alto rio Negro, é oportuno também citar os ocorridos na década de 1970, quando o país era controlado por militares, e elaborou seu Plano de Integração Nacional, que incluía um programa de obras de infraestrutura com o objetivo de "integrar geopoliticamente a região" ao restante do país, e que desencadeou inúmeros impactos na região do alto rio Negro, visualizados especificamente, entre os anos de 1972 e 1975, com a instalação de postos da Fundação Nacional do Índio (Funai) e de trabalhadores de empresas contratadas para a abertura da BR-307 (ligação entre São Gabriel e Cucuí) e de um trecho da rodovia Perimetral Norte (BR-210), hoje abandonada.

Em 1985, o governo brasileiro propôs o Projeto Calha Norte (PCN), com o propósito de impulsionar a presença governamental na região amazônica, com base na estratégia político-militar de ocupação e de defesa da fronteira, projeto esse que desencadeou inúmeros conflitos entre os militares e as comunidades indígenas localizadas nas calhas do rio Negro, que se sentiram ameaçadas. Essa situação foi agravada pela descoberta de ouro na serra do Traíra por indígenas Tukano do Tiquié, dando início a uma "febre" que se alastrou por vários pontos da região, deslocando indígenas e atraindo garimpeiros de outras partes do país, bem como os moradores de São Gabriel e, em seguida, empresas de mineração, que invadiram a serra do Traíra e a região do alto Içana (ISA, 2006).

Como já foi assinalado, esses acontecimentos ora elencados não se desenrolaram passivamente, os povos indígenas da região reagiram 
e se organizaram em torno do controle e gerenciamento de suas terras, reivindicando a criação de áreas contínuas de terras indígenas e, como fruto dessa mobilização, a conquista de seus direitos com a demarcação e regularização das terras indígenas na década de 1990. Cabe frisar que essa luta foi encabeçada pela Federação das Organizações Indígenas do Rio Negro (Foirn), que também desempenhou importante papel na formulação da Constituição de 1988 (PERES, 2003).

Atualmente a região do alto rio Negro vivencia um momento singular em que as associações indígenas formais, articuladas à Foirn, solidificam seu propósito acerca da gestão de seus territórios mediante a elaboração e implementação de propostas pautadas na noção de desenvolvimento sustentável, a exemplo do Programa Regional de Desenvolvimento Indígena Sustentável (PRDIS), e, mas recentemente, da criação do Sistema de Sustentabilidade do Rio Negro. No relatório "Construindo Políticas Públicas através do Programa Regional de Desenvolvimento Indígena Sustentável do Rio Negro", é destacado que o PRDIS deve realizar atividades integradas com o Estado, concernente às suas políticas públicas em prol dos povos indígenas, bem como com as organizações não governamentais, de forma "a construir e implementar um tipo de desenvolvimento que tenha o jeito de ser dos povos e que valorize a diversidade e os conhecimentos tradicionais, garantindo um novo patamar de bem-estar para as comunidades" (FOIRN/ISA, 2003: 15).

É importante assinalar que já está em andamento na região projetos, os quais se constituem parte integrante do PRDIS, a título de exemplo, podem-se citar os implementados no rio Içana, habitado por Baniwa e Coripaco, onde há alguns anos são realizadas pesquisas sobre a diversidade e sustentabilidade da produção de pimenta jiquitaia; manejo do arumã (fibra utilizada na fabricação de artesanato), manejo de recurso pesqueiro, dentre outros. Esses projetos são realizados com a assessoria do Instituto Socioambiental (ISA), agente responsável pela captação de recursos financeiros, particularmente junto a organizações estrangeiras, e que viabilizam a execução das propostas visando o desenvolvimento sustentável da região.

Essas ações vinculadas ao PRDIS são hoje conjugadas a novas perspectivas conceituais, que se consubstanciam em novos projetos, como o Sistema de Sustentabilidade do Rio Negro, criado recentemente (em 2012) em parceria com o Governo do Estado do Amazonas, por meio da Secretaria de 
Estado para os Povos Indígenas (Seind). Em termos gerais, esse sistema tem como objetivo central buscar receitas e fazer o gerenciamento dos recursos para potencializar, entre outras propostas, "as produções indígenas nas áreas da biotecnologia, agrobiodiversidade, agroflorestal, do ecoturismo, mineração (com exceção da Terra Indígena Yanomami), cosméticos, artesanatos, plantas medicinais, na criação de animais de pequeno porte (piscicultura, aves, suínos e outros), no pagamento de serviços ambientais e contribuição dos profissionais indígenas" (SEIND, 2012). Conforme divulgado pela Foirn, mediante essa parceria será possível viabilizar a identidade indígena no desenvolvimento regional sustentável, por meio da criação de um sistema de sustentabilidade socioeconômico e cultural para aquela região do Estado.

Considera-se que a mobilização dos povos indígenas conduzida por suas lideranças e organizações formais visando à implementação de projetos pautados na noção de desenvolvimento sustentável, realizada com a ajuda de parceiros (instituições governamentais e do terceiro setor, particularmente o ISA), constitui-se como parte das estratégias atuais dos povos indígenas da região, visando garantir a autonomia e o direito de definir os rumos de suas histórias. Nesse processo são imprescindíveis as alianças, pois elas fortalecem suas estratégias em torno da reivindicação de políticas públicas adequadas que extrapolem o modelo atual e que sejam capazes de garantir seus territórios e a diversidade cultural que representam.

\section{Considerações finais}

De acordo com Peres (2003), o rio Negro é a região onde mais se desenvolveu o fenômeno associativo indígena, assinalando que no decorrer da última década essa malha associativa cresceu aceleradamente, sendo esse fenômeno motivado pela mobilização dos povos indígenas na luta pela proteção dos seus territórios e da diversidade cultural da região.

A Federação das Organizações do Rio Negro (Foirn), em relatório divulgado em fevereiro de 2012, relaciona a lista atualizada das associações que estão afiliadas a ela, num total de 90 , criadas no âmbito das comunidades que se organizam formalmente, seguindo um modelo ocidental de organização, mediante o qual surge um tipo de líder igualmente diferente do tradicional (daquele que nasce no interior da cultura de cada povo), ou seja, um líder 
"qualificado" para assumir o papel de interlocutor dos diálogos e negociações interculturais, portador do discurso político-cultural em defesa dos territórios dos povos indígenas.

Entende-se que esse fenômeno associativo faça parte das atuais estratégias dos povos indígenas visando à sustentabilidade da região, em tempos em que, por força de mudanças em seus territórios, fazem-se necessárias novas estratégias que, somadas às tradicionais, lhes propiciem garantirem essa sustentabilidade. Esses povos sabem que no contexto atual a demarcação e homologação das terras indígenas não são suficientes para mantê-las, em razão disso fortalecem sua organização formal e estabelecem alianças mediante as quais conseguem estruturar propostas como o Programa Regional de Desenvolvimento Indígena Sustentável (PRDIS) e o Sistema de Sustentabilidade do Rio Negro.

Nesse sentido, o discurso ambientalista e, sobretudo, a incorporação de propostas pautadas na noção de desenvolvimento sustentável, consubstanciase em estratégias que têm se mostrado eficazes aos povos indígenas que vivem na região, possibilitando-os construir um futuro pautado nas suas culturas e no modo tradicional de explorar seus territórios, mantendo um diálogo estreito com os conhecimentos do mundo ocidental. Vale destacar que tudo isso ocorre mediante negociações, as quais não excluem conflitos e assimetrias entre os agentes indígenas e não indígenas envolvidos nesse processo.

\section{Notas}

${ }^{1}$ Conferir o relatório Amazonas Indígena: um mapeamento das Instituições e da produção bibliográfica sobre os Povos Indígenas no Amazonas. Núcleo de Estudos da Amazônia Indígenas. PPGAS - Museu Amazônico, 2009.

\section{Referências}

ALBERT, B. O ouro canibal e a queda do céu: uma crítica xamânica da economia política da natureza (Yanomami). In: Pacificando o branco: cosmologias do contato no norte-amazônico. ALBERT, Bruce; RAMOS, Alcida Rita (Orgs.). São Paulo: Editora Unesp / Imprensa Oficial do Estado, 2002.

ALMEIDA, A. W. B. de.; SHIRAISHI NETO, J.; MARTINS, C. C. Guerra Ecológica nos Babaçuais: o processo de devastação dos palmeirais, a elevação do 
preço de commodities e o aquecimento do mercado de terras na Amazônia. São Luís: MIQCB, 2005.

CABALZAR, A. Organização social Tuyuka. Dissertação de Mestrado. Departamento de Antropologia Social, Universidade de São Paulo. São Paulo, 1995.

CAVALCANTE, C. (Org.). Meio Ambiente, desenvolvimento sustentável e políticaspúblicas. 2. ed. São Paulo: Fundação Joaquim Nabuco, 1999.

CNUMAD - Comissão Mundial sobre o Meio Ambiente e Desenvolvimento. Nosso Futuro Comum. Rio de Janeiro: FGV, 1991.

FEDERAÇÃO DAS ORGANIZAÇÕES INDÍGENAS DO RIO NEGRO (FOIRN/ISA). Povos Indígenas do Rio Negro: uma introdução à diversidade socioambiental do noroeste da Amazônia brasileira. São Gabriel da Cachoeira: Foirn; São Paulo: ISA, 2006. Associações Filiadas à Foirn. São Gabriel da Cachoeira: Foirn, 2012.

FURTADO, C. O Mito do Desenvolvimento Econômico. Rio de Janeiro: Paz e Terra, 1998.

LEFF, E. Ecologia, capital e cultura: a territorialização da racionalidade ambiental. Petrópolis, RJ: Vozes, 2009.

JACKSON, J. The Fish People: linguistic exogamia e Tukano identity in northwest Amazonia. Cambridge: University Press, 1983.

LIMA, A. C. de S. Povos Indígenas no Brasil contemporâneo: de tutelados a "organizados". In: Povos Indígenas: projetos e desenvolvimento II. SOUZA, C. N. I. de S. et. al. Brasília: Paralelo 15; Rio de Janeiro: Laced, 2010.

LEITE LOPES, J. S. Sobre processo de "ambientalização" dos conflitos e sobre dilemas da participação. Horizontes Antropológicos. Porto Alegre, ano 12, n. $25,2006$.

MORIN, E; KERN, Anne Brigitte. Terra-Pátria. Porto Alegre: Sulina, 2000.

PARESCHI, A. C. C. Projetismo e Desenvolvimento Sustentável: o caso dos Pequenos Projetos. In: Hileia - Revista de Direito Ambiental da Amazônia, n.o 3, Manaus, Edições do Governo do Estado do Amazonas / Secretaria de 
Cultura / UEA, 2004.

PERES, S. C. Cultura, politica e identidade na Amazônia: o associativismo indígena no baixo rio Negro. Campinas, SP, 2003. Tese de Doutorado em Ciências Sociais, Departamento de Antropologia, Instituto de Filosofia e Ciências Humanas da Universidade Estadual de Campinas.

PIMENTA, J. O caminho da sustentabilidade entre os Ashaninka do rio Amônia - alto Juruá (AC). In: Povos Indígenas: projetos e desenvolvimento II. SOUZA, C. N. I. de S. et. al. Brasília: Paralelo 15; Rio de Janeiro: Laced, 2010. SECRETARIA DE ESTADO PARA OS POVOS INDÍGENAS (SEIND). Participação da Secretaria na criação do Sistema de Sustentabilidade do Rio Negro. Disponível em: http://portaldaseind.blogspot.com.br/. Acessado em: março de 2012. 